\title{
CALCULATION OF LONG-TERM FILTRATION IN A POROUS MEDIUM
}

\author{
Ludmila I. Kuzmina', Yuri V. Osipov', Nikita V. Vetoshkin ${ }^{2}$ \\ ${ }^{1}$ National Research University Higher School of Economics, Moscow, RUSSIA \\ ${ }^{2}$ National Research Moscow State University of Civil Engineering, Moscow, RUSSIA
}

\begin{abstract}
The filtration problem in a porous medium is an important part of underground hydromechanics. Filtration of suspensions and colloids determines the processes of strengthening the soil and creating waterproof walls in the ground while building the foundations of buildings and underground structures. It is assumed that the formation of a deposit is dominated by the size-exclusion mechanism of pore blocking: solid particles pass freely through large pores and get stuck at the inlet of pores smaller than the diameter of the particles. A onedimensional mathematical model for the filtration of a monodisperse suspension includes the equation for the mass balance of suspended and retained particles and the kinetic equation for the growth of the deposit. For the blocking filtration coefficient with a double root, the exact solution is given implicitly. The asymptotics of the filtration problem is constructed for large time. The numerical calculation of the problem is carried out by the finite differences method. It is shown that asymptotic approximations rapidly converge to a solution with the increase of the expansion order.
\end{abstract}

Keywords: filtration, porous medium, suspended and retained particles, mathematical model, asymptotics

\section{РАСЧЕТ ДОЛГОВРЕМЕННОЙ ФИЛЬТРАЦИИ В ПОРИСТОЙ СРЕДЕ}

\author{
Л.И. Кузьмина, Ю.В. Осипов ${ }^{2}$, Н.В. Ветоикин ${ }^{2}$ \\ ${ }^{1}$ Национальный исследовательский университет «Высшая школа экономики», г. Москва, РОССИЯ \\ ${ }^{2}$ Национальный исследовательский Московский государственный строительный университет, \\ г. Москва, РОССИЯ
}

\begin{abstract}
Аннотация: Рассматривается задача фильтрации в пористой среде - важная составная часть подземной гидромеханики. Задачи фильтрации суспензий и коллоидов описывают процессы укрепления грунта и создания водонепроницаемых стен в грунте при строительстве фундаментов зданий и подземных сооружений. Предполагается, что при образовании осадка основную роль играет механикогеометрический механизм блокирования пор: твердые частицы беспрепятственно проходят через большие поры и застревают на входе пор, размеры которых меньше диаметра частиц. Одномерная математическая модель фильтрации монодисперсной суспензии включает уравнение массообмена взвешенных и осажденных частиц и кинетическое уравнение роста осадка. Для блокирующего коэффициента фильтрации с двукратным корнем приводится точное решение в неявном виде. Строится асимптотика задачи фильтрации при большом значении времени. Численный расчет задачи выполнен методом конечных разностей. Показано, что с ростом порядка асимптотические приближения быстро сходятся к решению.
\end{abstract}

Ключевые слова: фильтрация, пористая среда, взвешенные и осажденные частицы, математическая модель, асимптотика

\section{INTRODUCTION}

The filtration of suspension in a porous medium is one of the most important problems of underground hydromechanics. The transport and retention of suspended particles in the pores of soil and rock are actual for the oil industry, 
strengthening of foundations, cleaning of surface waters and liquid industrial wastes [1-3]. The nature of filtration of the suspension in a porous medium depends on the composition of the fluid, the material of the porous medium, the ratio of the dimensions of the suspended particles and pores. We assume that the electrostatic and gravitational forces, the viscosity of the liquid, and the diffusion of the particles do not have a significant effect on the filtration process. If the particle and pore size distributions overlap, then the main mechanism of particle capture is size-exclusion interaction of particles and pores: the suspended particles of the suspension are freely transferred by the fluid flow through the large pores and get stuck in the small pore throats $[4,5]$.

The paper considers the filtration of identical solid suspended particles in a homogeneous porous medium. It is assumed that the distribution of the pore sizes is constant on each cross-section of the framework of the porous medium. A one-dimensional model of filtration, including the equation of mass transfer of suspended and retained particles and the kinetic equation of the deposit growth, is used below. The conditions of a constant concentration of suspended particles at the porous medium inlet and the absence of suspended and retained particles in a porous medium at the initial time determine a unique solution of the problem.

Some mathematical models of filtration have exact analytical solution [6-8]. In the absence of exact solutions, an asymptotics can be constructed [9-11]. If analytical solutions are unknown, numerical methods are used [12-15].

The exact solution of the filtration problem for a quadratic filtration coefficient with a multiple root is obtained in the paper. Since the solution is given by an implicit formula, an asymptotics is constructed to determine the properties of the solution for large time. It is shown that general limit conditions for the solution are insufficient to obtain an asymptotic expansion for $t \rightarrow \infty$, so it is necessary to use the exact solution for construction of the asymptotics.
In Section 2 a mathematical model of the filtration problem is presented, the exact solution of the problem is obtained in Section 3. In Section 4, asymptotics is constructed for large time; the results of numerical calculations are given in Section 5. Conclusion finalize the paper in Section 6.

\section{MATHEMATICAL MODEL}

The one-dimensional filtration problem of a monodisperse suspension in a porous medium is considered in a half-strip

$$
\Omega=\{(x, t): 0<x<1, t>0\} .
$$

The mathematical model of the filtration problem includes a hyperbolic system of two first-order equations with unknown concentrations of suspended particles $C(x, t)$ and retained particles $S(x, t)$

$$
\begin{gathered}
\frac{\partial C}{\partial t}+\frac{\partial C}{\partial x}+\frac{\partial S}{\partial t}=0 \\
\frac{\partial S}{\partial t}=\Lambda(S) C
\end{gathered}
$$

with boundary and initial conditions

$$
\begin{gathered}
\left.C\right|_{x=0}=1 ; \\
\left.C\right|_{t=0}=0 ;\left.\quad S\right|_{t=0}=0 .
\end{gathered}
$$

Here $\Lambda(S)$ is a decreasing nonnegative function, which is called the filtration coefficient.

The inconsistency of conditions (3), (4) at the origin leads to the discontinuity of the solution. The discontinuity line $t=x$ is called the concentrations front of the suspended and retained particles. It is a mobile boundary of two phases - a suspension and an empty porous medium. Before the concentrations front in the domain 


$$
\Omega_{0}=\{(x, t): 0 \leq x \leq 1,0<t<x\}
$$

the solution is zero; in the domain

$$
\Omega_{S}=\{(x, t): 0 \leq x \leq 1, t>x\}
$$

the solution is positive. At the front $t=x$, the solution $C(x, t)$ has a strong discontinuity (the suspended particles concentration has a gap); the solution $S(x, t)$ has a weak discontinuity (the retained particles concentration is continuous, but has a break, that is, a derivative jump occurs).

During the filtration, the retained particles concentration increases, and the number of free small pores of the porous medium is reduced. With prolonged filtration, more and more suspended particles pass unobstructed through the large pores without precipitation, and the growth rate of the retained particles concentration slows down. When all small pores are blocked by the particles, the formation of the deposit ceases, and the suspended particles pass freely through the porous medium. The maximum value of the retained particles concentration $S_{\max }$ is the minimum positive root of $\Lambda(S)$. Such filtration coefficient is called a blocking coefficient.

Consider the third-order polynomial with a double root

$$
\Lambda(S)=(1-S)^{2}+a(1-S)^{3}, a>0 .
$$

Below, the exact solution of the problem (1) (4) with the blocking filtration coefficient (5) is constructed by the methods used in $[16,17]$.

\section{EXACT SOLUTION}

First, we determine the solution at the porous medium inlet $x=0$. According to (3), equation (2) takes the form

$$
\frac{\partial S}{\partial t}=(1-S)^{2}+a(1-S)^{3}
$$

Division of the variables and integration with respect to $t$ yields

$$
\int_{0}^{t} \frac{\partial S / \partial t}{(1-S)^{2}+a(1-S)^{3}} d t=t
$$

Using the initial condition (4), the integral in the left side of (7) can be written in the form

$$
\int_{0}^{S_{0}} \frac{d S}{(1-S)^{2}+a(1-S)^{3}}=t
$$

Calculation of the integral in the left side of (8) gives

$$
\begin{aligned}
& \int_{0}^{S_{0}}\left(-\frac{a}{(1-S)}+\frac{1}{(1-S)^{2}}+\frac{a^{2}}{(1+a-a S)}\right) d S= \\
& =\left.\left(a \ln (1-S)+\frac{1}{1-S}-a \ln (1+a-a S)\right)\right|_{0} ^{S_{0}} .
\end{aligned}
$$

The solution $S_{0}(t)$ at the porous medium inlet is determined in implicit form

$$
a \ln \left(\frac{\left(1-S_{0}\right)(1+a)}{1+a-a S_{0}}\right)+\frac{S_{0}}{1-S_{0}}=t
$$

Now the solution for $x>0$ can be obtained. From equation (2)

$$
C=\frac{\partial S / \partial t}{\Lambda(S)}
$$

Substitution of (11) into equation (1) yields

$$
\frac{\partial}{\partial t}\left(\frac{\partial S / \partial t}{\Lambda(S)}\right)+\frac{\partial}{\partial x}\left(\frac{\partial S / \partial t}{\Lambda(S)}\right)+\frac{\partial S}{\partial t}=0 .
$$

Using the equality 


$$
\begin{aligned}
& \frac{\partial}{\partial x}\left(\frac{\partial S / \partial t}{\Lambda(S)}\right)=\frac{1}{\Lambda(S)} \frac{\partial^{2} S}{\partial x \partial t}- \\
& -\frac{\Lambda^{\prime}(S)}{\Lambda^{2}(S)} \frac{\partial S}{\partial x} \frac{\partial S}{\partial t}=\frac{\partial}{\partial t}\left(\frac{\partial S / \partial x}{\Lambda(S)}\right)
\end{aligned}
$$

the equation (12) can be written in the form

$$
\frac{\partial}{\partial t}\left(\frac{\partial S / \partial t}{\Lambda(S)}+\frac{\partial S / \partial x}{\Lambda(S)}+S\right)=0
$$

Integration of (14) with respect to the variable $t$ gives

$$
\frac{\partial S / \partial t}{\Lambda(S)}+\frac{\partial S / \partial x}{\Lambda(S)}+S=K(x)
$$

Since the solution is zero in the domain $\Omega_{0}$, the function $S(x, t)$ and its partial derivatives are zero for $t=0$. Then the integration constant is determined from (15): $K(x)=0$. Equation (15) takes the form

$$
\frac{\partial S / \partial t}{\Lambda(S)}+\frac{\partial S / \partial x}{\Lambda(S)}+S=0
$$

Multiplication of (16) by $\Lambda(S)$ yields

$$
\frac{\partial S}{\partial t}+\frac{\partial S}{\partial x}+S \Lambda(S)=0
$$

Denote the characteristic variables

$$
\tau=t-y, \quad x=y .
$$

The partial derivatives in new variables

$$
\frac{\partial S}{\partial t}=\frac{\partial S}{\partial \tau} ; \quad \frac{\partial S}{\partial x}=\frac{\partial S}{\partial y}-\frac{\partial S}{\partial \tau} .
$$

Equation (17) takes the form

$$
\frac{\partial S}{\partial y}+S \Lambda(S)=0
$$

Division of the variables and integration of equation (19) with respect to the variable $y$ gives

$$
\int_{0}^{y} \frac{\partial S / \partial y}{S \Lambda(S)} d y=-y
$$

Using the condition

$$
\left.S(y, \tau)\right|_{y=0}=S_{0}(\tau)
$$

the integral in the left side of equation (20) can be written in a form

$$
\int_{S_{0}}^{S} \frac{d S}{S \Lambda(S)}=-y
$$

The integral in the left side of equation (22) can be calculated for the filtration coefficient (5)

or

$$
\begin{aligned}
& \left.\left(\frac{1}{a+1} \ln S+(a-1) \ln (1-S)+\frac{a^{3}}{a+1} \ln (a+1-a S)+\frac{1}{1-S}\right)\right|_{S_{0}} ^{S}=-y, \\
& \frac{1}{a+1} \ln \frac{S}{S_{0}}+(a-1) \ln \frac{1-S}{1-S_{0}}+\frac{a^{3}}{a+1} \ln \frac{a+1-a S}{a+1-a S_{0}}+\frac{1}{1-S}=\frac{1}{1-S_{0}}-y .
\end{aligned}
$$

In the variables $x, t$ the relation (24) has the form

$$
\frac{1}{a+1} \ln \frac{S}{S_{0}}+(a-1) \ln \frac{1-S}{1-S_{0}}+\frac{a^{3}}{a+1} \ln \frac{a+1-a S}{a+1-a S_{0}}+\frac{1}{1-S}=\frac{1}{1-S_{0}}-x
$$


where $S_{0}(t)$ is determined by formula (10).

The relation (27) defines in an implicit form the exact solution $S(x, t)$ of problem (1) - (4) in the domain $\Omega_{S}$. For a known function $S(x, t)$, the solution $C(x, t)$ is determined by formula (11).

\section{ASYMPTOTICS FOR LARGE TIME}

4.1 Asymptotic solution at the inlet $x=0$ Asymptotics $S_{0}^{a s}(t)$ at the inlet of the porous medium for $t \rightarrow \infty$ is constructed in a form

$$
\begin{aligned}
& S_{0}^{a s}=1-\frac{b_{1}}{t}-\frac{b_{2} \ln t+b_{3}}{t^{2}}- \\
& -\frac{b_{4} \ln ^{2} t+b_{5} \ln t+b_{6}}{t^{3}}+O\left(\frac{\ln ^{3} t}{t^{4}}\right),
\end{aligned}
$$

where

$$
f=O\left(\frac{\ln ^{3} t}{t^{4}}\right)
$$

is a function satisfying the estimate

$$
|f| \leq \text { const } \cdot \ln ^{3} t / t^{4}
$$

Substitution of the series (26) into the left side of equation (10) yields

$$
\begin{aligned}
& \frac{t}{b_{1}}-\left(a+\frac{b_{2}}{b_{1}^{2}}\right) \ln t+\left(a \ln \left((1+a) b_{1}\right)-1-\frac{b_{3}}{b_{1}^{2}}\right)+ \\
& +\frac{\left(b_{2}^{2}-b_{1} b_{4}\right) \ln ^{2} t+\left(a b_{1}^{2} b_{2}+2 b_{2} b_{3}-b_{1} b_{5}\right) \ln t}{b_{1}^{3} t}+ \\
& +\frac{a b_{1}^{2} b_{3}+b_{3}^{2}-a^{2} b_{1}^{4}-b_{1} b_{6}}{b_{1}^{3} t}+O\left(\frac{\ln ^{3} t}{t^{2}}\right)=t .
\end{aligned}
$$

Equation of the coefficients with the same powers $t^{k} \ln ^{l} t$ gives a recurrent system of equations with the unknowns $b_{i}, i=1, \ldots, 6$ :

$$
\begin{gathered}
\frac{1}{b_{1}}=1 ; \quad a+\frac{b_{2}}{b_{1}^{2}}=0 ; \quad a \ln \left((1+a) b_{1}\right)-1-\frac{b_{3}}{b_{1}^{2}}=0 ; \\
b_{2}^{2}-b_{1} b_{4}=0 ; \quad a b_{1}^{2} b_{2}+2 b_{2} b_{3}-b_{1} b_{5}=0 ; \\
a b_{1}^{2} b_{3}+b_{3}^{2}-a^{2} b_{1}^{4}-b_{1} b_{6}=0 .
\end{gathered}
$$

Substitution of the obtained coefficients into the expansion (26) yields

$$
\begin{aligned}
& S_{0}^{a s}(t)=1-\frac{1}{t}+\frac{a \ln t+A}{t^{2}}-\frac{a^{2} \ln ^{2} t}{t^{3}}- \\
& -\frac{\left(2 a A-a^{2}\right) \ln t+\left(A^{2}-A a-a^{2}\right)}{t^{3}}
\end{aligned}
$$

where

$$
A=A(0)=1-a \ln (1+a) .
$$

\subsection{Asymptotic solution for $x>0$}

The asymptotic solution of problem (1) - (4) for $t \rightarrow \infty$ is constructed in a form

$$
\begin{aligned}
& S^{a s}(y, \tau)=1-\frac{a_{1}}{\tau}-\frac{a_{2} \ln \tau+a_{3}}{\tau^{2}}- \\
& -\frac{a_{4} \ln ^{2} \tau+a_{5} \ln \tau+a_{6}}{\tau^{3}}+O\left(\frac{\ln ^{3} \tau}{\tau^{4}}\right) .
\end{aligned}
$$

Substitution of the expansion (29) into the relation (24) gives the recurrent system of equations with the unknowns $a_{i}, i=1, \ldots, 6$. The asymptotic solution $S^{a s}(y, \tau)$ is obtained similarly to Sec. 4.1

$$
\begin{aligned}
& S^{a s}(y, \tau)=1-\frac{1}{\tau}+\frac{a \ln \tau+A}{\tau^{2}}-\frac{a^{2} \ln ^{2} \tau}{\tau^{3}}- \\
& -\frac{\left(2 a A-a^{2}\right) \ln \tau+\left(A^{2}-a A-a^{2}-y\right)}{\tau^{3}},
\end{aligned}
$$

where $A=A(y)=1-a \ln (1+a)-y$.

The asymptotic solution $C^{a s}(y, \tau)$ is obtained from the relation (11) 


$$
C^{a s}(y, \tau)=1-\frac{y}{\tau^{2}}+O\left(\frac{\ln ^{3} \tau}{\tau^{3}}\right)
$$

Next terms of the asymptotics (31) can be obtained from the equation (1). In the characteristic variables (18), equation (1) has the form

$$
\frac{\partial C}{\partial y}+\frac{\partial S}{\partial t}=0
$$

Substitution of the expansion (30) into the equation (32) and integration of (32) with respect to $y$ using the condition (3) yields

$$
\begin{aligned}
& C^{a s}(y, \tau)=1-\frac{y}{\tau^{2}}+\frac{2 a \ln \tau+2 A-a+y}{\tau^{3}} y-\frac{3 a^{2} \ln ^{2} \tau+a(6 A-5 a+3 y) \ln \tau}{\tau^{4}} y- \\
& -\frac{6-10 a-4 a^{2}-9 y+5 a y+2 y^{2}+\left(10 a^{2}-12 a+6 a y\right) \ln (1+a)+6 a^{2} \ln ^{2}(1+a)}{2 \tau^{4}} y .
\end{aligned}
$$

In the variables $x, t$ the asymptotic solution of the problem (1) - (4) for $t \rightarrow \infty$ takes the form

$$
\begin{aligned}
& S^{a s}(x, t)=1-\frac{1}{t-x}+\frac{a \ln (t-x)+A}{(t-x)^{2}}-\frac{a^{2} \ln ^{2}(t-x)+\left(2 a A-a^{2}\right) \ln (t-x)+\left(A^{2}-a A-a^{2}-x\right)}{(t-x)^{3}} ; \\
& C^{a s}(x, t)=1-\frac{x}{(t-x)^{2}}+\frac{2 a \ln (t-x)+2 A-a+x}{(t-x)^{3}} x-\frac{3 a^{2} \ln ^{2}(t-x)+a(6 A-5 a+3 x) \ln (t-x)}{(t-x)^{4}} x- \\
& -\frac{6-10 a-4 a^{2}-9 x+5 a x+2 x^{2}+\left(10 a^{2}-12 a+6 a x\right) \ln (1+a)+6 a^{2} \ln ^{2}(1+a)}{2(t-x)^{4}} x .
\end{aligned}
$$

Here $A=A(x)=1-a \ln (1+a)-x$.

\section{NUMERICAL CALCULATION}

Calculation of the solution of the problem (1)(4) and its asymptotics (33), (34) is performed for $a=1$. In Fig. 1 graphs of exact $S_{0}$ and asymptotic solutions $S_{i}$ of various orders at the porous medium inlet $x=0$ are presented.

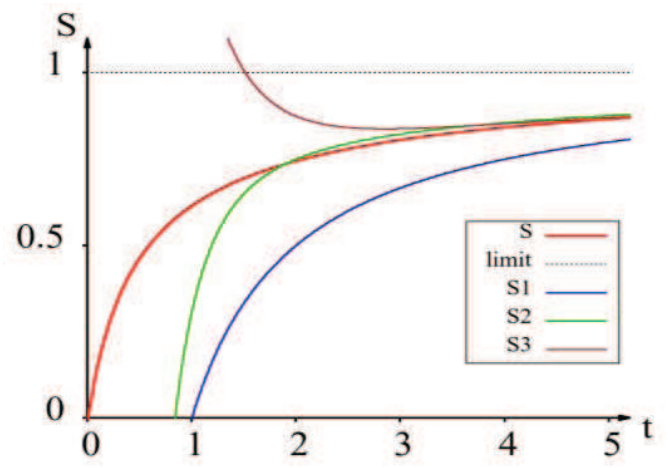

Figure 1. Retained concentration $S_{0}(t)$ for $x=0$.
Laboratory experiments allow determining the concentrations of suspended and retained particles at the filter outlet at any time after breakthrough. Therefore, the solution for $x=1$ is of the utmost interest.

Graphs of the exact solution $C, S$ and asymptotic solutions $C_{i}, S_{i}$ of various orders at the porous medium outlet are shown in Fig. 2, 3.

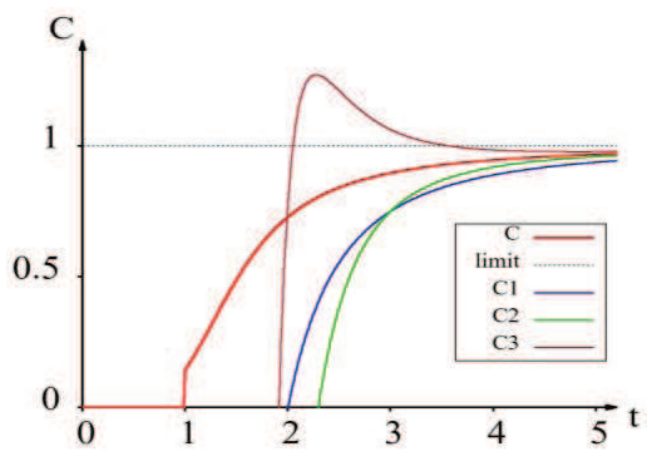

Figure 2. Suspended concentration $\left.C(x, t)\right|_{x=1}$. 


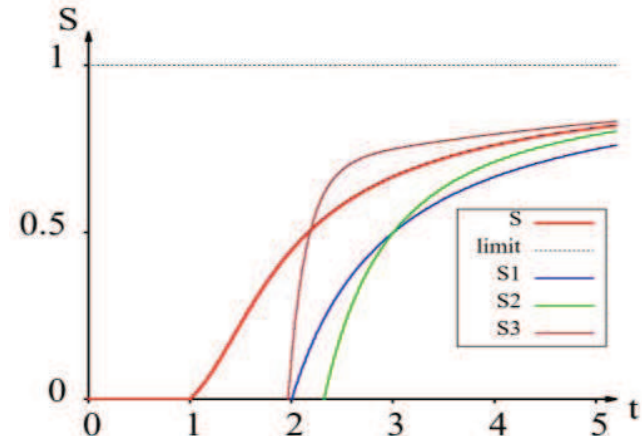

Figure 3. Retained concentration $\left.S(x, t)\right|_{x=1}$.

The graphs show that the asymptotics converge rapidly to the solution and the solution does not exceed the limit values

$$
\begin{aligned}
& \lim _{t \rightarrow \infty} C(x, t)=\left.C(x, t)\right|_{x=0}=1 ; \\
& \lim _{t \rightarrow \infty} S(x, t)=S_{\max }=1 .
\end{aligned}
$$

The convergence of the asymptotics improves with increasing order of the asymptotic approximation.

\section{CONCLUSION}

The one-dimensional mathematical model of filtration of a monodisperse suspension in a porous medium with size-exclusion mechanism for particles retention is considered. The exact solution of the problem for the blocking filtration coefficient with double root is obtained. An asymptotics for $t \rightarrow \infty$ is constructed. It is shown that the asymptotic solution rapidly converges to the limiting values.

Asymptotics near the porous medium inlet and near the concentrations front of the suspended and retained particles is constructed by substituting asymptotic expansions into the filtration equations and boundary conditions [9, 18]. In contrast to this, it was found out that the equations (1), (2) and the limit conditions (35) do not determine uniquely the asymptotic solution of the filtration problem for $t \rightarrow \infty$. To obtain the asymptotics, it is necessary to use the exact solution of the problem.

It is proved that the asymptotic solution of the filtration problem with a double root blocking filtration coefficient includes terms of the form $\ln ^{k} t / t^{l}$. Note that in the case of a simple root the asymptotics decreases exponentially [19]. Determination of asymptotic expansion for the filtration coefficient with a root of multiplicity above two requires a separate study.

In contrast to the implicit form of the exact solution, the asymptotics of the filtration problem is constructed in explicit form. The explicit dependence of the suspended and retained particles concentrations on time and coordinate makes it possible to reduce the amount and cost of field studies and laboratory experiments [20,21].

\section{REFERENCES}

1. Civan F. Reservoir Formation Damage: Fundamentals, Modeling, Assessment and Mitigation. 2nd ed., Gulf Professional Pub., Amsterdam, 2007.

2. Li S., Liu R., Zhang Q., Zhang $X$. Protection Against Water or Mud Inrush in Tunnels by Grouting: A Review. // Journal of Rock Mechanics and Geotechnical Engineering, 8, 2016, pp. 753-766.

3. Noubactep C., Caré S. Dimensioning Metallic Iron Beds for Efficient Contaminant Removal. // Chemical Engineering Journal, 163, 2010, pp. 454-460.

4. Santos A., Bedrikovetsky P., Fontoura S. Analytical Micro Model for Size Exclusion: Pore Blocking and Permeability Reduction. // Journal of Membrane Science, 308, 2008, pp. 115-127.

5. Bashtani F., Ayatollahi S., Habibi A., Masihi M. Permeability Reduction of Membranes During Particulate Suspension Flow; Analytical Micro Model of Size Exclusion Mechanism. // Journal of Membrane Science, 435, 2013, pp. 155164. 
6. You Z., BedrikovetskyP., Kuzmina L. Exact Solution for Long-Term Size Exclusion Suspension - Colloidal Transport in Porous Media. // Abstract and Applied Analysis, 2013, article ID 680693.

7. Kuzmina L., Osipov Yu. Calculation of Filtration of Polydisperse Suspension in a Porous Medium. // MATEC Web of Conferences, 86, 2016, 01005.

8 Kuzmina L., Osipov Yu. Filtration Model of the Unsteady Suspension Flow in a Porous Medium. // MATEC Web of Conferences, 117, 2017, 00097.

9. You Z., Osipov Yu.V., Bedrikovetsky P., Kuzmina L.I. Asymptotic Model for Deep Bed Filtration. // Chemical Engineering Journal, 258, 2014, pp. 374-385.

10. Kuzmina L.I., Osipov Y.V., Galaguz Y.P. A Model of Two-Velocity Particles Transport in a Porous Medium. // International Journal of Non-linear Mechanics, 93, 2017, pp. 1-6.

11. Kuzmina L.I., Osipov Yu.V. Asymptotic Solution for Deep Bed Filtration with Small Deposit. // Procedia Engineering, 111, 2015, pp. 491-494.

12. Galaguz Y.P., Safina G.L. Calculation of the Filtration in a Heterogeneous Porous Medium. // MATEC Web of Conferences, 117, 2017, 00052.

13. Galaguz Y.P., Safina G.L. Modeling of filtration of 2-types Particles Suspension in a Porous Medium. // MATEC Web of Conferences, 117, 2017, 00053.

14. Sefrioui N., Ahmadi A., Omari A., Bertin H. Numerical Simulation of Retention and Release of Colloids in Porous Media at the Pore Scale. // Colloids and Surfaces A: Physicochemical and Engineering Aspects, 427, 2013, pp. 33-40.

15. Kuzmina L.I., Osipov Y.V., Galaguz Y.P. Numerical and Asymptotic Modeling of a Filtration Problem with the Initial Deposit. // International Journal for Computational Civil and Structural Engineering, 13(3), 2017, pp. 70-76.
16. Vyazmina E.A., Bedrikovetskii P.G., Polyanin A.D. New Classes of Exact Solutions to Nonlinear Sets of Equations in the Theory of Filtration and Convective Mass Transfer. // Theoretical Foundations of Chemical Engineering, 41(5), 2007, pp. 556-564.

17. Bedrikovetsky P.G., You Z., Badalyan A., Osipov Y., Kuzmina L. Analytical Model for Straining-Dominant LargeRetention Depth Filtration. // Chemical Engineering Journal, 330, 2017, pp. 11481159.

18. Kuzmina L.I., Osipov Yu.V. Particle Transportation at the Filter Inlet. // International Journal for Computational Civil and Structural Engineering, 10(3), 2014, pp. 17-22.

19. Kuzmina L.I., Osipov Yu.V. Asymptotic Model of Filtration in Almost Stationary Mode. // International Journal for Computational Civil and Structural Engineering, 12(1), 2016, pp. 158-163.

20. Faramarzi L, Rasti A, Abtahi S.M. An Experimental Study of the Effect of Cement and Chemical Grouting on the Improvement of the Mechanical and Hydraulic Properties of Alluvial Formations. // Journal of Construction \& Building Materials, 126, 2016, pp. 32-43.

21. Bedrikovetsky P.G., Marchesin D., Checaira F., Serra A.L., Resende E. Characterization of Deep Bed Filtration System from Laboratory Pressure Drop Measurements. // Journal of Petroleum Science and Engineering, 32(3), 2001, pp. 167-177.

\section{СПИСОК ЛИТЕРАТУРЫ}

1. Civan F. Reservoir Formation Damage: Fundamentals, Modeling, Assessment and Mitigation. 2nd ed., Gulf Professional Pub., Amsterdam, 2007.

2. Li S., Liu R., Zhang Q., Zhang $X$. Protection Against Water or Mud Inrush in 
Tunnels by Grouting: A Review. // Journal of Rock Mechanics and Geotechnical Engineering, 8, 2016, pp. 753-766.

3. Noubactep C., Caré S. Dimensioning Metallic Iron Beds for Efficient Contaminant Removal. // Chemical Engineering Journal, 163, 2010, pp. 454-460.

4. Santos A., Bedrikovetsky P., Fontoura S. Analytical Micro Model for Size Exclusion: Pore Blocking and Permeability Reduction. // Journal of Membrane Science, 308, 2008, pp. 115-127.

5. Bashtani F., Ayatollahi S., Habibi A., Masihi M. Permeability Reduction of Membranes During Particulate Suspension Flow; Analytical Micro Model of Size Exclusion Mechanism. // Journal of Membrane Science, 435, 2013, pp. 155164.

6. You Z., BedrikovetskyP., Kuzmina L. Exact Solution for Long-Term Size Exclusion Suspension - Colloidal Transport in Porous Media. // Abstract and Applied Analysis, 2013, article ID 680693.

7. Kuzmina L., Osipov Yu. Calculation of Filtration of Polydisperse Suspension in a Porous Medium. // MATEC Web of Conferences, 86, 2016, 01005.

8 Kuzmina L., Osipov Yu. Filtration Model of the Unsteady Suspension Flow in a Porous Medium. // MATEC Web of Conferences, 117, 2017, 00097.

9. You Z., Osipov Yu.V., Bedrikovetsky P., Kuzmina L.I. Asymptotic Model for Deep Bed Filtration. // Chemical Engineering Journal, 258, 2014, pp. 374-385.

10. Kuzmina L.I., Osipov Y.V., Galaguz Y.P. A Model of Two-Velocity Particles Transport in a Porous Medium. // International Journal of Non-linear Mechanics, 93, 2017, pp. 1-6.

11. Kuzmina L.I., Osipov Yu.V. Asymptotic Solution for Deep Bed Filtration with Small Deposit. // Procedia Engineering, 111, 2015, pp. 491-494.

12. Galaguz Y.P., Safina G.L. Calculation of the Filtration in a Heterogeneous Porous
Medium. // MATEC Web of Conferences, 117, 2017, 00052.

13. Galaguz Y.P., Safina G.L. Modeling of filtration of 2-types Particles Suspension in a Porous Medium. // MATEC Web of Conferences, 117, 2017, 00053.

14. Sefrioui N., Ahmadi A., Omari A., Bertin H. Numerical Simulation of Retention and Release of Colloids in Porous Media at the Pore Scale. // Colloids and Surfaces A: Physicochemical and Engineering Aspects, 427, 2013, pp. 33-40.

15. Kuzmina L.I., Osipov Y.V., Galaguz Y.P. Numerical and Asymptotic Modeling of a Filtration Problem with the Initial Deposit. // International Journal for Computational Civil and Structural Engineering (Международный журнал по расчету гражданских и строительных конструкций), 13(3), 2017, pp. 70-76.

16. Vyazmina E.A., Bedrikovetskii P.G., Polyanin A.D. New Classes of Exact Solutions to Nonlinear Sets of Equations in the Theory of Filtration and Convective Mass Transfer. // Theoretical Foundations of Chemical Engineering, 41(5), 2007, pp. 556-564.

17. Bedrikovetsky P.G., You Z., Badalyan A., Osipov Y., Kuzmina L. Analytical Model for Straining-Dominant LargeRetention Depth Filtration. // Chemical Engineering Journal, 330, 2017, pp. 11481159.

18. Kuzmina L.I., Osipov Yu.V. Particle Transportation at the Filter Inlet. // International Journal for Computational Civil and Structural Engineering (Международный журнал по расчету гражданских и строительных конструкций), 10(3), 2014, pp. 17-22.

19. Kuzmina L.I., Osipov Yu.V. Asymptotic Model of Filtration in Almost Stationary Mode. // International Journal for Computational Civil and Structural Engineering (Международный журнал по расчету гражданских и строительных конструкций), 12(1), 2016, pp. 158-163. 
20. Faramarzi L, Rasti A, Abtahi S.M. An Experimental Study of the Effect of Cement and Chemical Grouting on the Improvement of the Mechanical and Hydraulic Properties of Alluvial Formations. // Journal of Construction \& Building Materials, 126, 2016, pp. 32-43.

21. Bedrikovetsky P.G., Marchesin D., Checaira F., Serra A.L., Resende E. Characterization of Deep Bed Filtration System from Laboratory Pressure Drop Measurements. // Journal of Petroleum Science and Engineering, 32(3), 2001, pp. 167-177.

Liudmila I. Kuzmina, Candidate of Physical and Mathematical Sciences, Associate Professor, Department of Applied Mathematics, National Research University Higher School of Economics, 101000, Russia, Moscow, Myasnitskaya st., 20, tel. +7(495) $7729590 * 15219$, E-mail: lkuzmina@hse.ru.

Yuri V. Osipov, Candidate of Physical and Mathematical Sciences, Associate Professor, Department of Applied Mathematics, Moscow State University of Civil Engineering, 129337, Russia, Moscow, Yaroslavskoe Shosse, 26, tel. +7(499)1835994,

E-mail: yuri-osipov@mail.ru.

Nikita V. Vetoshkin, Undergraduate student in Computer Science, Moscow State University of Civil Engineering, 129337, Russia, Moscow, Yaroslavskoe Shosse, 26, tel. +7(499)1835994, e-mail: getz1165@gmail.com.

Кузьмина Людмила Ивановна, доцент, кандидат физико-математических наук, Департамент прикладной математики, Национальный исследовательский университет «Высшая школа экономики»; 101000, г. Москва, ул. Мясницкая, д. 20, тел. +7(495) $7729590 * 15219$; e-mail: 1kuzmina@hse.ru.

Осипов Юрий Викторович, доцент, кандидат физикоматематических наук, кафедра прикладной математики Национального исследовательского Московского государственного строительного университета; 129337, Россия, г. Москва, Ярославское шоссе, д. 26; тел. +7(499)1835994;

E-mail: yuri-osipov@mail.ru.

\begin{tabular}{lrrr} 
Ветошкин & Никита & \multicolumn{1}{c}{ Владимирович, } & студент \\
бакалавриата & по & направлению & подготовки \\
«Информатика & и & вычислительная & техника»
\end{tabular}

Национального исследовательского Московского государственного строительного университета; 129337, Россия, г. Москва, Ярославское шоссе, д. 26; тел. +7(499)1835994; e-mail: getz1165@gmail.com. 